EDITOR'S CHOICE

\section{See Commentary, p 146}

${ }^{1}$ INSERM, U669, Paris, France ${ }^{2}$ Univ Paris-Sud and Univ Paris Descartes, UMR-S0669, Paris, France ${ }^{3}$ Department of Epidemiology, WHO

Collaborative Centre, Institut National de Recherche et de Sécurité (INRS)

Vandœurre-lès-Nancy, France ${ }^{4}$ Département des Conditions du Travail et Facteurs Humains, Direction des Ressources Humaines, Société Nationale des Chemins de Fer, Paris, France ${ }^{5}$ INSERM, U420, Faculty of Medicine,

Vandoeuvre-lès-Nancy, France

\section{Correspondence to}

Dr Nearkasen Chau, INSERM, U669, 8 rue du Breuil, F-54180 Heillecourt, France; nearkasen.chau@wanadoo.fr

Accepted 6 August 2009

Published Online First

7 September 2009

\title{
Roles of age, length of service and job in work-related injury: a prospective study of 446120 person-years in railway workers
}

\author{
N Chau, ${ }^{1,2}$ P Wild, ${ }^{3}$ D Dehaene, ${ }^{4}$ L Benamghar, ${ }^{5}$ J M Mur, ${ }^{5}$ C Touron ${ }^{4}$
}

\begin{abstract}
Objectives Because work-related injuries are common and yet the mechanisms through which various types of injuries relate to age, length of service and job remain unknown, this study assessed the role of age, length of service and job in work-related injury.

Methods Prospective study of all 164814 permanently employed male workers at the French national railway company during 1998-2000, based on the company's injury database: 446120 person-years, 15195 injuries with working days lost, coded using the company's injury classification, which is derived from that of the French health insurance scheme. We investigated the incidence of 10 types of injury: fall on same level, fall to lower level, handling materials/machine parts during assembly, handling objects, lifting/handling equipment, collision with/by moving objects, collision with/by vehicles, operating machines/equipment, using hand tools and other injuries. Data were analysed using negative binomial regression.
\end{abstract}

Results Workers aged $<25$ years were subject to a higher injury risk from handling materials/machine parts during assembly, and collision with/by moving objects or vehicles. Older workers, especially those aged 50-55 years, were subject to a higher risk of fall and injury resulting from lifting/handling materials/equipment/ objects or from collision with/by moving objects/vehicles. Using hand tools was a risky task for workers aged $<30$ or $\geq 40$ years. The relative risk decreased steadily with increasing length of service with the company, from 2.6 for 1 year to 1.0 for $\geq 30$ years, and the slope of the trend is stronger for fall to lower level, lifting/handling materials/ equipment and collision with/by moving objects.

Conclusion Younger and older ages and shorter length of service are at risk for various types of injuries.

Preventive measures should improve working conditions, especially for younger/older ages, provide knowledge through specific training during the first years in a job and help workers to be more aware of risks associated with their age, years of employment and job.

Every year, 120 million work-related and 210000 fatal injuries occur in the world ${ }^{1}$ and these have severe socioeconomic consequences. ${ }^{2}{ }^{3}$ In 2003, there were 721227 injuries with days lost (incidence rate $4.1 \%$, 36 million days lost), 48774 injuries leading to permanent disability and 661 fatal injuries under the French general health insurance scheme (17.6 million workers). ${ }^{3}$

Every year, young people start work lacking job knowledge and experience ${ }^{4}$; research has revealed them to be subject to a high risk of injury. ${ }^{4-15}$ These research studies define young age as $<20$ or

\section{What this paper adds}

Work-related injuries are common and yet the mechanisms through which various types of injuries relate to age, length of service and job remain unknown, although these factors play an important role. It has been difficult to separate the role of age and length of service in most studies because of their collinear nature, especially when they were categorised in two classes only. This investigation is needed because it is a prospective study on a large population of sufficient participants in various age brackets and lengths of service in a number of job groups.

This study demonstrates that (1) workers aged $<25$ years were subject to a higher injury risk from handling materials/and machine parts during assembly, collision with/by moving objects or vehicles and using hand tools; (2) older workers were subject to a higher risk of fall and injury resulting from handling materials/machine parts during assembly, lifting/handling objects or equipment, collision with/by moving objects or vehicles and using hand tools; (3) age did not influence falls on same level or injury when operating machines/ equipment; (4) the relative risk decreased steadily with increasing length of service, and this trend was similar for nearly all types of injuries; and (5) risks associated with various jobs, when controlling age and length of service, reflected both occupational activities and working environment. The findings highlight the benefit of improving working conditions, providing specific training in terms of job knowledge, task performance and occupational hazard assessment from a worker's first years in a job, as well as ensuring that a worker's skill corresponds with his occupational activities. Workers should be helped to gain awareness of risks relating to their job, age and experience.

$<30$ years, which embraces both adolescence and young adulthood. Some studies have highlighted the injury role of diseases and disabilities ${ }^{10} 16$ common among workers older than approximately 40 years. ${ }^{17-20}$ Diseases and disabilities alter both working skill and the way in with occupational hazards are monitored and assessed. However, there are few studies of the part played by older age. One study has showed a 2.6-fold higher risk for workers $>45$ years old compared with those aged 
$<30$ years. ${ }^{21}$ A relationship has been discovered between cumulated physical job demands and injury, and this represents a twofold higher risk for workers $>40$ years old than for younger workers. ${ }^{10}$ Older ages are associated with lack of postural control, ${ }^{22} 23$ favouring a fall, and the risk of falling to lower level may be higher than that of falling on same level because it is more difficult to control one's balance on less stable raised platforms or on stairs. Lower physical strength and disabilities of older workers ${ }^{1824}$ mean that the injury risk can be greater among them for the most demanding tasks or those that require greater strength or skill. ${ }^{25} 26$ Note that demanding occupations generate both injuries and disabilities. ${ }^{10} 1213$ The impact of older age on injury is a public health problem in Europe because of the lengthening of working life, which results in more people working at an older age. Note that older ages are associated with injuries with longer days lost. ${ }^{27}$

The role of lack of experience in injury, which is measured by length of service, is well known, but some studies have focused on the first 5 years in a given job ${ }^{6} 28$ because of the small samples used. Many workers are confronted by rapid turnover, which leaves them with a lack of job knowledge and experience. This issue affects most jobs and different ages, and thus many older workers may accumulate disabilities and insufficient job knowledge and experience. Age and experience can be distinguished as individual factors, which change with the course of time but which could be controlled in epidemiologic design. Older age is often associated with greater experience, neglecting the role of disease and disability, whereas experience and disability do in fact play opposite roles in injury. Two questions are of interest. First, what length of service reflects a lack of experience? Second, what are the respective roles of younger and older age, length of service and job, and are they related to injury type? We need to understand the mechanisms, through which these factors contribute to injury, as potential targets for injury reduction programmes, which go beyond conventional methods by considering the various risks to which different age groups are subject. It has been difficult to separate the role of age and length of service in most studies because of their collinear nature, especially when they were categorised in two classes only. ${ }^{11}$ A prospective study on a large population of sufficient participants in various age brackets and lengths of service in a number of job groups was therefore necessary. We assumed that gaining experience is a long, gradual process, that there is a link between injury and younger and older age independent of experience and job, and that risk depends on the type of injury.

We assessed the part played by age, length of service with the company and job in various types of injury among French railway workers. We chose this population because many jobs are represented (mechanics, drivers, maintenance workers, construction workers, painters, welders, boilermakers, manual workers, employees, managers, etc) and it therefore constitutes a wide population with enough workers in different age categories, with different lengths of service and in different jobs. Note that the annual injury incidence rate of these workers is the same as for workers within the French general insurance scheme. ${ }^{3}$

\section{METHODS}

\section{Population}

The study population consisted of all male participants working with a permanent work contract in the French National Railway Company at some time between 1 January 1998 and 31 December 2000 (3 years). This population was selected from a basic population of all employees comprising 207872 workers, of whom 20106 did not have permanent contracts (fixed period or temporary jobs, 9.7\%). There were 34601 female workers (16.6\%), of whom 22952 had permanent contracts and 11649 did not have permanent contracts.

Thus, our study population comprised 164814 male workers with permanent contracts $(79.3 \%)$. For each subject, the day of hiring as well as for each year the active presence in the company and the job were available.

\section{Study design}

The population was followed up for the incidence of workrelated injuries from 1 January 1998 to 31 December 2000. The survey used the company's systematic database of injuries with sick leave due to work-related accidents (health disorders were excluded) to identify incident cases. This injury database was created by our department to better understand the injury mechanisms for all worker categories and to monitor the injury risk for various jobs, age groups and lengths of service. For each injury, the system recorded the worker's identification number and an injury description. These data were collected at the time of the injury by the department prevention office in presence of the injured worker. An injury was defined as bodily damage, irrespective of its severity, resulting from an accident with at least one working day lost, in addition to the day on which the accident occurred, and for which the subject received compensation. Fatal injuries were also included ( 25 deaths).

Outcomes were identified using the company's injury classification, drawn up based on that of the French general health insurance scheme ${ }^{3}$ : falls on same level, falls to lower level, handling materials/machine parts during assembly, handling objects, lifting/handling equipment, collision with/by moving objects, collision with/by vehicles, operating machines/equipment, using hand tools and other injuries.

The personnel database has been constructed by the company personnel office, and is used among others to establish the salary advices and medical examinations by occupational physicians. The database thus contains data for all the staff and is valid. For each new recruitment, one identification number is attributed to the worker for all his careers. It is constructed as follows: year of birth, followed by the month of recruitment, the order number of recruitment for the month and one key-letter that is used to verify the figures in the identification number (eg, 43-11-228-T). The personnel database contains socioadministrative data, recruitment date, jobs performed and their periods during each worker's career. The precise date of quitting the firm, especially for retirement, was not available, but this concerned a relatively small proportion of participants. Because of the young age of retirement ( 50 years for train drivers and 55 years for the others), deaths were also very rare.

To ensure a sufficient number of participants in each category, age was categorised in seven classes: <25, 25-29, 30-34, 35-39, $40-44,45-49$ and $\geq 50$ years and length of service in 10 groups: $<1,1,2,3-4,5-9,10-14,15-19,20-24,25-29$ and $\geq 30$ years. Job categories were identified using the SNCF's job classification $^{30}$ : train customer accompaniment operators; mechanical/ diagnostic/electrotechnical operators and boilermakers-welders; railway maintenance operators; signposting/telecommunication/energy-electric traction/specialised mechanical operators; other design/construction/basic equipment/rolling equipment operators; transport production operators; traffic operators; other operational production operators; train drivers; and other jobs.

Injury data and the personnel database were first transferred to the company's Working Conditions and Human Factors Department, after first deleting the workers' names, then to the INSERM research team for statistical analysis. The two 
databases were then merged using the worker identification numbers. This procedure ensured that the workers' names were not known by the two SNCF and INSERM teams. The final database was not accessible to the company.

This work to obtain data for prevention purposes was presented first to the National Committee for Hygiene, Safety and Working Conditions, then to 674 committees for hygiene, safety and working conditions in various departments, the regional division committees, 23 safety and work regional advisors and 280 work safety coordinators (in charge of prevention in each department).

The study was also presented to all the personnel via the journal of the company. No worker expressed his/her opposition to the survey. However, we did not seek informed consent from workers because it was difficult to contact them all.

During the 3-year follow-up period, which represents 446120 person-years, 15195 injuries were observed.

\section{Data analysis}

For each subject, the precise date of hiring as well as for each year the active presence in the company and the occupation were available. However, the precise date of leaving the company was not available. The statistical control of the followup was therefore approximate for the participants who quitted the firm during the follow-up period and was as follows: a subject who was not present in the firm for a year $Y$ contributed 0.5 person-year for the year Y-1 (this assumes that he quitted the firm at the median date, the 30th June of that year). This procedure only concerns a small proportion of the train drivers who reached the age of 50 years during the followup period as all the other workers take their retirement at 55 years. The person-years as well as the injuries were attributed individually and year-wise to the occupation held by each subject every year and to the age group and category of length of service for this year. The injury incidence rate per 1000 person-years, that is, the number of injuries occurring in any time cell defined by the independent variables (groups of age, length of service and job), divided by the total person-years cumulated in this time cell, was analysed using negative binomial regression, which is an extension of the Poisson regression taking into account overdispersion (ie, the fact that because of unmeasured factors, the variance of the rates was larger than predicted by the usual Poisson approximation). The independent variables considered were regrouped categories of age, length of service and job using STATA V.10 (Stata, College Station, Texas, USA). Before analysis, the individual data were collapsed into total numbers of injuries and person-years in each combination of the independent variables de facto dropping empty cells. The results are expressed as adjusted risk ratios (RRs) and 95\% confidence intervals.

\section{RESULTS}

The injury incidence rate for the 3-year monitoring period was 34.1 per 1000 person-years. Principal injury types were falls on same level $(24.6 \%)$, handling materials/machine parts during assembly (22.4\%), falls to lower level (16.7\%), handling objects $(7.8 \%)$, using hand tools $(5.7 \%)$, collision with/by vehicles $(4.5 \%)$, collision with/by moving objects (3.6\%), lifting/handling equipment $(3.1 \%)$, operating machines/equipment $(2.8 \%)$ and other injuries $(8.7 \%)$. The frequency of participants having two injuries or more was $1.1 \%$ (injury incidence rate 3.3 ).

Table 1 and figure 1 show that the injury incidence rate decreased steadily with increasing age, from 54.1 for workers aged $<25$ to 24.9 years for those aged $50-55$ years, and with increasing length of service, from approximately 55.9 for workers employed for 1 year to 19.0 for those employed for $\geq 30$ years. The most exposed jobs were mechanical/diagnostic/electrotechnical operators and boilermakers-welders (injury incidence rate 79.7), railway maintenance operators (injury incidence rate 67.1), signposting/telecommunication/energy-electric traction/ specialised mechanical operators (injury incidence rate 43.2) and transport production operators (injury incidence rate 57.8). Multiple adjustment using the negative binomial regression model reveals a discreet $U$-curve for the RRs of age groups reaching the minimum for the 30-34 years age group, whereas the roles of length of service ( $R R$ decreased steadily from 2.6 to 1.0 for the reference group ( $\geq 30$ years)) and some job categories $(1.7<\mathrm{RRs}<2.9)$ were highly significant. Workers who had worked for $<1$ year had lower risk than those who had worked for $1-2$ years. Figure 1 also shows that the injury incidence rate increases with length of service during the first 4 years of the career for the workers aged $<25$ years, and during the $1-2$ first years of the career for those aged 26-34 years. When analysing the younger age groups separately from the older age groups, adjusted for occupation, this increase in the incidence rate was less pronounced than in the raw rates, but the incidence rates were significantly higher for the 1-2 first years of length of service compared with the first year of service. Cross-tabulation of rates by age, length of service by job are provided as online supplements. This seems true for most types of injuries and most jobs (online supplement figures of incidence rates). Note that the workers with $<3$ years of service were rare among the participants aged $\geq 35$ years (214 vs 13956, 22404 and 3290 person-years for the $<25,25-29$ and 30-34 years age groups, respectively). It may be indicated that among the participants aged $<30$ years, the proportion of those working in the highest risk employments, that is, the mechanical/diagnostic/electrotechnical operators and boilermakers-welders increases steadily from $10 \%$ of the participants with $<1$ year seniority to $20 \%$ in the group with 5 years seniority. No such trend was seen in the participants aged $\geq 30$ years; among them the proportion of participants in this group lies between $7 \%$ and $14 \%$ depending on the seniority.

Table 2 shows the RRs computed using negative binomial regression models for various injury types. Incidence rates for each injury type are provided as online supplements. We found that the RRs decreased steadily with increasing length of service for all injury types, but the trends are stronger for injury risk due to fall to lower level, handling materials/machine parts during assembly, lifting/handling equipment and collision with/by moving objects. Those aged $<25$ years had a higher injury risk due to handling materials/machine parts during assembly, using hand tools and collision with/by moving objects or vehicles (compared with the workers aged 25-44 years). Older workers and especially those aged 50-55 years experienced a higher risk of falling on same level or to lower level or injury resulting from handling materials/machine parts during assembly, lifting/ handling objects/equipment, or from collision with/by moving objects or vehicles (compared with the workers aged 30-44 years). Using hand tools was a risky task for workers aged $<30$ or $\geq 40$ years.

\section{DISCUSSION}

Among workers $<25$ years old, we noted a higher injury risk due to handling materials/machine parts during assembly, using hand tools and collision with/by moving objects or vehicles, whereas among older ages (especially those aged $50-55$ years), there was a higher injury risk due to fall on same level or to lower level, handling materials/machine parts during assembly, lifting/ 
Table 1 Work-related injury incidence rate and adjusted risk ratio according to age, length of service and job

\begin{tabular}{|c|c|c|c|c|c|}
\hline All sample & $\begin{array}{l}\begin{array}{l}\text { Number of } \\
\text { person-years }\end{array} \\
446120\end{array}$ & $\begin{array}{l}\begin{array}{l}\text { Number of occupational } \\
\text { injuries }\end{array} \\
15195 \\
\end{array}$ & $\begin{array}{l}\begin{array}{l}\text { Incidence rate per } 1000 \\
\text { person-years }\end{array} \\
34.1 \\
\end{array}$ & \multicolumn{2}{|c|}{$\begin{array}{l}\text { Adjusted risk ratio and } \\
95 \% \mathrm{Cl}\end{array}$} \\
\hline \multicolumn{6}{|l|}{ Age (years) } \\
\hline $25-29$ & 43383 & 2040 & 47.0 & 0.86 & 0.72 to 1.04 \\
\hline $30-34$ & 43332 & 1772 & 40.9 & 0.83 & 0.70 to 0.98 \\
\hline $35-39$ & 78296 & 2676 & 34.2 & 0.86 & 0.75 to 1.00 \\
\hline $50-55$ & 62744 & 1561 & 24.9 & 1.00 & \\
\hline \multicolumn{6}{|l|}{ Length of service (years) } \\
\hline$<1$ & 15454 & 592 & 38.3 & 1.87 & 1.49 to 2.34 \\
\hline 1 & 13446 & 751 & 55.9 & 2.64 & 2.12 to 3.29 \\
\hline 2 & 11856 & 664 & 56.0 & 2.72 & 2.18 to 3.39 \\
\hline $3-4$ & 13614 & 656 & 48.2 & 2.29 & 1.84 to 2.84 \\
\hline $25-29$ & 74855 & 2215 & 29.6 & 1.41 & 1.24 to 1.61 \\
\hline$\geq 30$ & 49534 & 938 & 19.0 & 1.00 & \\
\hline \multicolumn{6}{|l|}{ Job category } \\
\hline Train customer accompaniment operators & 25945 & 693 & 26.7 & 1.00 & \\
\hline $\begin{array}{l}\text { Mechanical/diagnostic/electrotechnical } \\
\text { operators and boilermakers-welders }\end{array}$ & 44248 & 3525 & 79.7 & 2.87 & 2.53 to 3.26 \\
\hline Railway maintenance operators & 44155 & 2963 & 67.1 & 2.49 & 2.19 to 2.83 \\
\hline $\begin{array}{l}\text { Signposting/telecommunication/energy- } \\
\text { electric traction/specialized mechanical } \\
\text { operators }\end{array}$ & 26882 & 1161 & 43.2 & 1.66 & 1.45 to 1.91 \\
\hline $\begin{array}{l}\text { Other conception/construction/basic } \\
\text { equipment/rolling equipment operators }\end{array}$ & 46824 & 922 & 19.7 & 0.78 & 0.67 to 0.90 \\
\hline
\end{tabular}

Risk ratios were computed using negative binomial regression models featuring age, length of service and job.

handling objects or equipment, collision with/by moving objects or vehicles, and using hand tools. We found a steady decreasing trend in rates associated with length of service for all injury types. However, among the workers aged $<35$ years, the incidence rate increased in the first years of employment. As this increase was found up to 4 years of service, we conclude that an

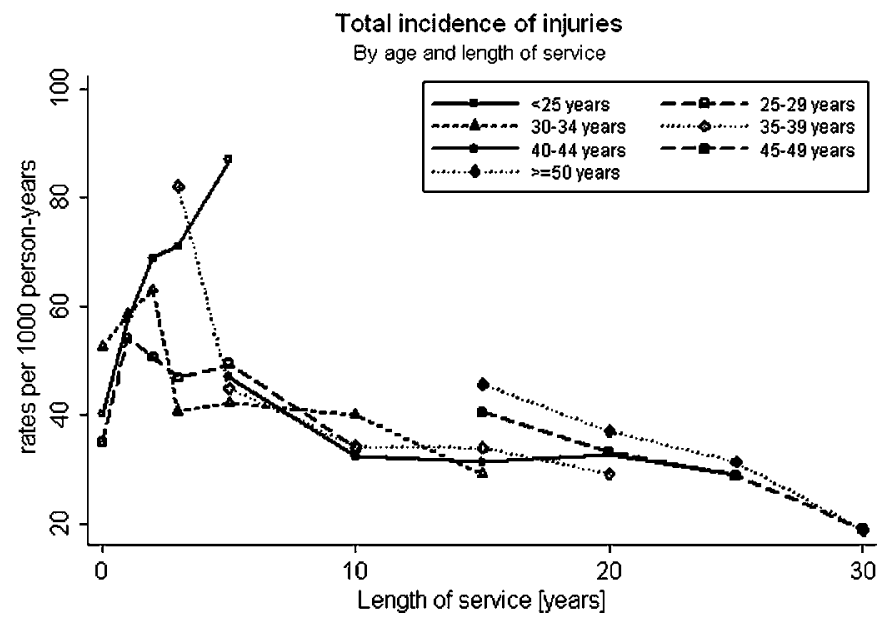

Figure 1 Incidence rate (per 1000 person-years) of injuries by age and length of service. experience of $<4$ years did not contribute to reduce the injury risk among those young workers.

These findings are important because they show the respective roles of age, experience and job in the mechanisms involved in various types of injury. Such issues represent a public health problem because of ageing of the working population and the rapid turnover of relatively inexperienced workers in many countries. The impact of rapid worker turnover on injury ${ }^{31}$ would be greater for older workers with reduced physical and mental abilities. ${ }^{18}$ Choosing French railway workers has several advantages. Many jobs are performed by this population. Length of service represents a good measure of job experience. A number of diseases/disabilities appear after the age of 40 years ${ }^{17}$ 18 and retirement age is 50 years for train drivers and 55 for the other workers, which provides a 40- to 55-year interval for examining the part played by older age. The injury incidence rate varies little from year to year. The data are confirmed and there were enough participants in the various age, length of service and job categories. A 3-year monitoring period was nevertheless selected to include enough injuries for statistical analysis. In this study we did not exclude those workers who had an injury before 1998 because having an injury is a risk factor for subsequent injury. ${ }^{32}$ Their exclusion would lead to a selection bias, and it is more appropriate to include all the personnel in the study. 
Table 2 Relationships of age and length of service according to occupational injury type (446 120 person-years, 15195 injuries): risk ratio adjusted for job and $95 \% \mathrm{Cl}$

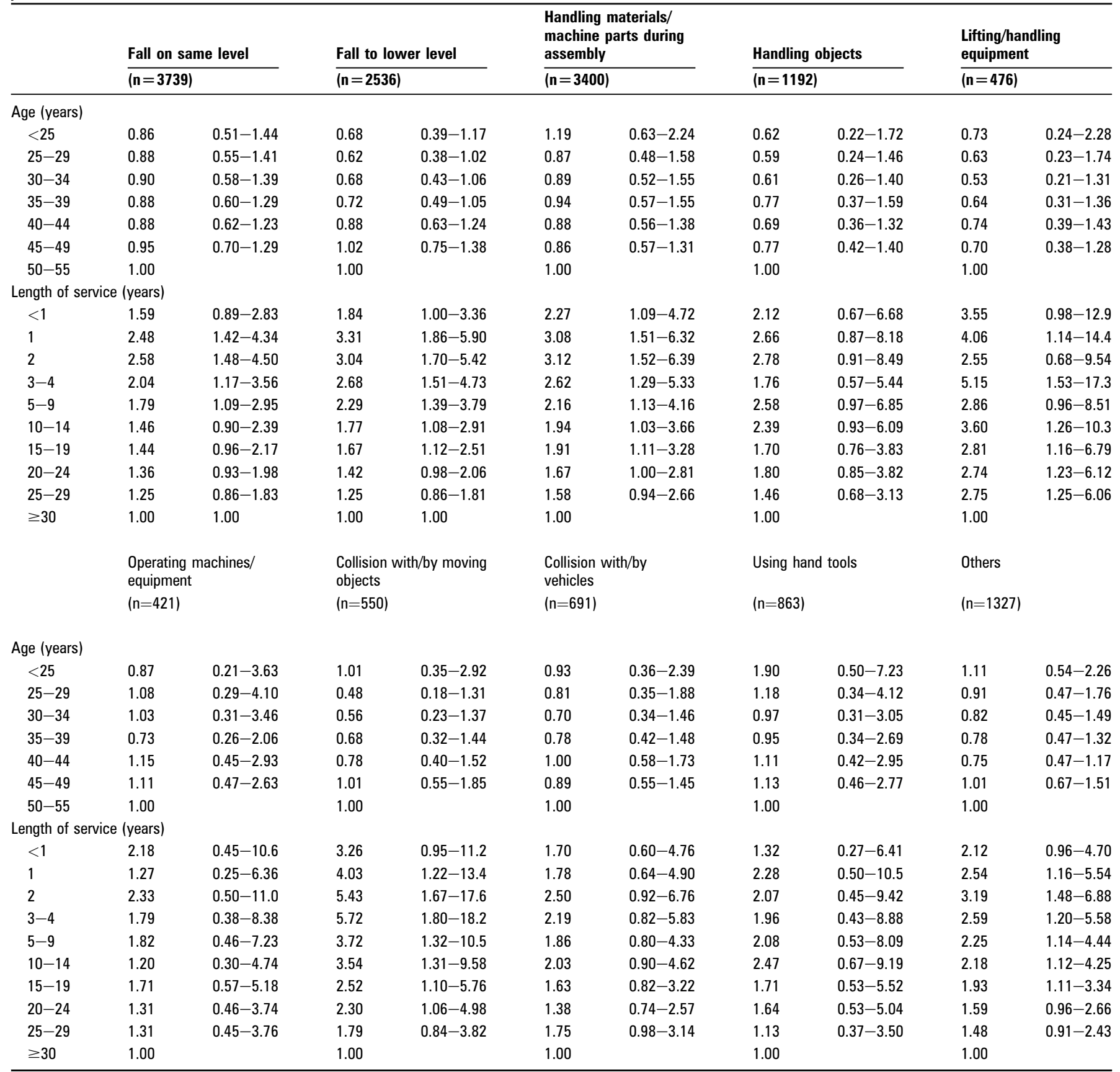

$\mathrm{n}$ indicate number of occupational injuries.

We found that workers aged $<25$ years had higher injury risk due to handling materials/machine parts during assembly, using hand tools and collision with/by moving objects or vehicles (compared with the workers aged 25-44 years). Note that several studies of us on various populations (construction workers, railway workers, general working population) have also found an increased injury risk among the workers aged $<30$ years when controlling or not a number of potential risk factors (job, length of service, occupational demands, age, sex, education, obesity, smoking, alcohol abuse, diseases, disabilities, fatigue, sleep disorders, leisure physical/sports activity, income). 561028 Other authors have found the same result for workers aged $<25$ or $<30$ years. ${ }^{7-9}$ The present study is a large investigation that confirms these findings by taking into account a number of categories of length of service and jobs using prospective data on a very large cohort. Our findings indicate that preventive measures aimed at reducing injury among younger workers should include training in handling materials/machine parts, using hand tools and assessing environmental hazards, such as moving objects and vehicles in workplaces.

We found that in the younger age groups the incidence rates increased in the first years of service. Our data suggest that in the first years of service, progressively more risky jobs would be assigned to young workers compared with older workers, although their experience and job knowledge remain lacking. ${ }^{4}$ However, the change in the mixture of jobs cannot explain the phenomenon alone as, among younger age groups, the incidence rates increase with length of service in several job groups (figures 
by job group) and for several types of injuries, and particularly in the highest risk job group, the incidence rates were higher in the second year of service than in the first. The workers should be followed up during their first years of service.

We found that injuries due to handling materials/machine parts during assembly, lifting/handling objects or equipment or to using hand tools related to older age and that this risk rose steadily from the age of 35 years onwards. This finding suggests that older workers with lower physical strength, ${ }^{24}$ physical and mental impairments (after $45,>30 \%$ of participants suffer from impairments) or disabilities ${ }^{17} 18$ are subject to higher injury risk, ${ }^{20}$ although they do not curtail their occupational activities or change their working environment. We also found that older workers were subject to a higher risk of falling and that this risk increased above the age of $40-45$ years. Falling often occurs when walking because balance-regulating mechanisms are overwhelmed by a destabilising event. Posture control is a complex sensorimotor function requiring central integration of multiple sensory afferences to select and execute a context-specific motor response leading to stabilisation of antigravity activity and gaze. Damage to any of these systems influences the common output of the posture control and therefore causes a fall. Our result may be explained by increased sensorial and cognitive disabilities, which are well known to favour falling ${ }^{17} 1833$ among participants aged $\geq 40$ years. ${ }^{17}$ Ageing healthy people have reduced posture control, associated with cognitive and brain structural involution, in unstable stance conditions and with diminished sensory input. ${ }^{22}$ Posture of 44- to 60-year-old participants is more sensitive to task concentration constraints than that of young participants. ${ }^{23}$ Older adults display greater body sway than the younger adults, when performing demanding tasks. ${ }^{34}$ Posture control demands concentration under certain circumstances, especially under dual task conditions, ${ }^{35}$ and interference occurs between activities of maintaining balance and performing mental tasks. ${ }^{36}$ Our study reveals that older workers were also subject to a higher injury risk due to collision with/by moving objects or vehicles. This result may be partly explained by a higher prevalence of visual, hearing and cognitive impairments, which steadily increase after 40 years of age ${ }^{18}$ and which are known to favour injuries. ${ }^{10} 1637$ An injury caused by a moving object often results from the subject not being able to avoid the object because he hears neither the object itself nor the warning message related to the moving object. A study has shown a relationship between warning sound and perceived urgency by the subject. ${ }^{38}$ Our findings are important because lengthening of working life produces more workers aged $>55$ years, and this agerelated risk trend suggests that these older workers are subject to high risk. Physical job performance requirements as well as tasks and environments involving excessive risk should be mitigated for workers aged $\geq 40$ years.

Our study shows that injury risk was highest during the first 2 years of employment and then decreased steadily with increasing length of service (except for workers aged $<25$ years). This trend was observed for all injury categories. Although some long service staff would be in safer jobs and younger workers may make more difficult tasks than older workers or those with disability when they work in teams, these findings show that gaining job experience represents a long, gradual, personal effort, which will produce maximum benefit after 30 years of employment. Job experience therefore appears to be an endless process of acquiring job knowledge, especially in relation to task performance and occupational hazard assessment. This may be explained by the large number of occupational hazards and their complex injury-causing mechanisms. Another railway worker study reported that environmental hazards were involved in $24.7 \%$, technical malfunctions in $16.0 \%$, insufficient work organisation in $13.7 \%$, lack of know-how/job knowledge in $22.8 \%$ and the other human factors in $31.9 \%$ of injuries. ${ }^{4}$ A number of occupational demands related to task performing (using hand tools, machine tools, vibrating platforms, handling objects, awkward postures, pace of work, physical workload, work at heights, adverse climates, exposure to noise, cold or heat) are also strong risk factors of injury. ${ }^{10}{ }^{21}$ It is therefore inappropriate to use job experience alone to reduce injury during a working life and recommendations should include earlier training, starting workers in low hazard conditions, limiting job turnovers and improved monitoring of hazard exposures that new workers encounter. ${ }^{12}$ Note that the workers who are not satisfied with their job and request for a job change are at an elevated injury risk. $^{6}$

Our study reveals that the mechanical/diagnostic/electrotechnical operators and boilermakers-welders, railway maintenance operators, transport production operators, signposting/ telecommunication/energy-electric traction and specialised mechanical operators had significantly high risks when adjusted for age and length of service. They featured greater risk of most injury types: handling materials/machine parts during assembly, lifting/handling equipment or objects, collision with/by moving objects or vehicles, operating machines/equipment or using hand tools. These workers often handle large/heavy objects or materials, often in hazardous environments (restricted work space, ground in poor condition and holes in ground, slippery ground, congested ground, sloping ground or railway embankment, reduced visibility at night), and they often stated they underestimated the risk. ${ }^{4}$ Note that the increasing injury risk during the first 4 years of service for participants aged $<25$ years and the steady decreasing risk according to increasing length of service were observed for most job categories (online supplement figures of incidence rates).

Our study has several strong points. It is a prospective study, which reveals the parts played by younger and older age, length of service and job in various injury types. As previously stated, the railway workers are employed in a number of jobs. Despite their collinear nature, ${ }^{11}$ enough participants in various age and length of service categories could be followed up and the large number of injuries in each cross-classified category allowed us to assess their respective roles. This study shows that analysing injuries of all types in combination does not reveal mechanisms, in which younger and older age, length of service and job factors are involved. This would explain why previous studies have revealed discrepancies regarding the role of younger and older age. $^{5-11}$

Interpretation of these findings must consider the study limitations. The study focused on male railway workers in permanent employment only. Female workers and non-permanently employed workers were excluded because of their relatively small numbers. Workers' jobs before their railway company career were neglected, although these are rare among workers in permanent employment. Only injuries with days lost were considered to avoid the accidents causing minor injuries. Analysis of beneficial and adverse effects of age and length of service was limited to workers aged $<55$ years because of retirement at this age. This did not allow investigation of workers aged $>55$ years who are predominantly affected by disabilities and most concerned by lengthening of working life. In addition, some older workers may have been moved to safer jobs, especially because of promotion. The follow-up period is rather limited but the loss to follow-up and censoring was to some extent 
controlled. We did not take into account certain potential confounders such as previous job history and previous accident history. Because of the young age of retirement, there would be few participants who were lost due to a premature mortality during the follow-up period. As we focused on participants with a permanent work contract, those who had quitted the company are very rare. The frequency of participants having two injuries or more was small. The injury risk found may be underestimated because of the well-known healthy worker effect. We investigated here the length of service with the company and not that in present job. Indeed, most participants have a very dominant job during their career. We should acknowledge that although the study population is very large, some adjusted RRs do not meet traditional levels of significance while their increasing or decreasing trends are often clear.

\section{CONCLUSION}

This study sheds light on the roles of younger and older age, length of service and job in injury-related mechanisms. Younger age favours injury due to handling materials/machine parts during assembly, collision with/by moving objects or vehicles and using hand tools, whereas older age (especially $50-55$ years) favours falling and injury due to handling materials/machine parts during assembly, lifting/handling objects or equipment, collision with/by moving objects or vehicles, and using hand tools, independently of experience and job. Length of service plays an injury protection role, independently of age and job, and the trend is stronger for fall to lower level, lifting/ handling materials/equipment and collision with/by moving objects. Job categories are affected by specific risks reflecting occupational activities. Our findings highlight the benefit of improving working conditions, providing training in terms of job knowledge, task performance and occupational hazard assessment from a worker's first years in a job, as well as ensuring that a worker's skill corresponds with his occupational activities. Workers should be helped to gain awareness of risks relating to their job, age and experience. However, this study has several limitations and the findings need to be confirmed on other populations.

Funding None.

Competing interests None.

Ethics approval This study was conducted with the approval of the Commission nationale de l'informatique et des libertés (CNIL), Paris, France.

Provenance and peer review Not commissioned; externally peer reviewed.

\section{REFERENCES}

1. International Labour Office. Encyclopedia of occupational health and safety, Vol 3 , 4th edn. Geneva: ILO, 1998.

2. Dembe AE. The social consequences of occupational injuries and illnesses. Am J Ind Med 2001:40:403-17.

3. Caisse nationale de l'assurance maladie des travailleurs salariés (CNAMTS). Statistiques nationales des accidents du travail, des accidents de trajet et des maladies professionnelles - 2003. Paris: CNAMTS, 2005.

4. Chau N, Gauchard G, Dehaene D, et al. Contributions of occupational hazards and human factors in occupational injuries and their associations with job, age and type of injuries in railway workers. Int Arch Occup Environ Health 2007;80: 517-25.

5. Chau N, Mur JM, Benamghar L, et al. Relationships between some individual characteristics and occupational accidents in the construction industry: a case-control study on 880 victims of accidents occurred during a two-year period. J Occup Health 2002:44:131-9

6. Chau N, Mur JM, Touron C, et al. Correlates of occupational injuries for various jobs in railway workers: a case-control study. J Occup Health 2004:46:272-80.
7. Cloutier $\mathbf{E}$. The effect of age on safety and work practices among domestic trash collectors in Québec. Saf Sci 1994;17:291-308.

8. McCaig LF, Burt CW, Stussman BJ. A comparison of work-related injury visits and other injury visits to emergency departments in the United States, 1995-1996. $J$ Occup Environ Med 1998; 40:870-5.

9. Salminen S. Have young workers more injuries than older ones? An international literature review. J Saf Res 2004;35:513-21.

10. Chau N, Bourgkard E, Bhattacherjee A, et al. Associations of job, living conditions and lifestyle with occupational injuries in working population: a population-based study. Int Arch Occup Environ Health 2008;81:379-89.

11. Blom DHJ, Pokorny MLI, Van Leeuwen P. The role of age and experience in bus drivers' accidents. Int J Epidemiol 1987:16:35-43.

12. Breslin FC, Tompa E, Zhao R, et al. The relationship between job tenure and work disability absence among adults: a prospective study. Accid Anal Prev 2008;40 368-75.

13. Leigh JP. Individual and job characteristics as predictors of industrial accidents. Accid Anal Prev 1986:18:209-16.

14. Cellier JM, Eyrolle H, Bertrand A. Effects of age and level of work experience on occurrence of accidents. Percept Mot Skills 1995;80:931-40.

15. Butani SJ. Relative risk analysis of injuries in coal mining by age and experience at present company. J Occup Accid 1988;10:209-16.

16. Zwerling C, Whitten PS, Davis CS, et al. Occupational injuries among workers with disabilities: the national health interview survey, 1985-1994. JAMA. 1997;278:2163-6.

17. Gauchard GC, Deviterne D, Guillemin F, et al. Prevalence of sensorial and cognitive disabilities and falls, and their relationships: a community-based study. Neuroepidemiology 2006;26:108-18.

18. Chau N, Ravaud JF, Otero Sierra C, et al. Prevalence of impairments and social inequalities: a community-based study in Lorraine. Rev Epidemiol Sante Publ 2005; 53:614-28

19. Barbotte $\mathbf{E}$, Guillemin F, Chau N. Lorhandicap Group. Prevalence of impairments, disabilities, handicaps and quality of life in the general population: a review of recent literature. Bull World Health Organ 2001;79:1047-55.

20. Chau N, Bhattacherjee A, Kunar BM. Lorhandicap Group. Relationship between job, lifestyle, age and occupational injuries. Occup Med (Lond) 2009;59 114-19.

21. Ghosh AK, Bhattacherjee A, Chau N. Relationships of working conditions and individual characteristics with occupational injuries: a case-control study in coal miners. J Occup Health 2004:46:470-80.

22. Sullivan EV, Rose J, Rohlfing T, et al. Postural sway reduction in aging men and women: relation to brain structure, cognitive status, and stabilizing factors. Neurobio Aging 2009;30:793-807.

23. Poulain I, Giraudet G. Age-related changes of visual contribution in posture control. Gait Posture 2008:27:1-7.

24. Mathiowetz V, Kashman N, Volland G, et al. Grip and pinch strength: normative data for adults. Arch Phys Med Rehabil 1985;66:69-74.

25. Khlat M, Ravaud JF, Brouard N, et al. The Lorhandicap Group. Occupational disparities in accidents and roles of lifestyle factors and disabilities. A populationbased study in North-eastern France. Public Health 2008;122:771-83.

26. Chau N, Khlat M. The Lorhandicap Group. Strong association of physical job demands with functional limitations among active people: a population-based study in Northeastern France. Int J Occup Environ Health 2009;82:857-66.

27. Gauchard GC, Chau N, Touron C, et al. Individual characteristics in occupational accidents due to imbalance: a case-control study in the employees of a railway company. Occup Environ Med 2003;60:330-5

28. Chau N, Mur JM, Benamghar L, et al. Relationships between certain individual characteristics and occupational accidents for various jobs in the construction industry: a case-control study. Am J Ind Med 2004;45:84-92.

29. Chau N, Benamghar L, Siegfried C, et al. Determinants of occupational fracture proneness: a case-control study in construction and railway workers. J Occup Health 2006:48:267-70.

30. French Railway National Society (SNCF). Observatoire des métiers: définition des métiers et des emplois repères associés. Paris: SNCF, 1998.

31. McGwin G, Taylor AJ, MacLennan PA, et al. Unsusual job activities as a risk factor for occupational injuries. Occup Med 2005;55:66-8.

32. Gauchard GC, Mur JM, Touron C, et al. Determinants of accident proneness: a casecontrol study in railway workers. Occup Med (Lond) 2006:56:187-90.

33. Cambois E, Désesquelles A, Ravaud JF. The gender disability gap. Popul Soc 2003;386:1-4

34. Prioli AC, Cardozo AS, de Freitas Junior PB, et al. Task demand effects on postural control in older adults. Hum Mov Sci 2006;25:435-46.

35. Woollacott MH, Shumway-Cook A. Attention and the control of posture and gait: a review of an emerging area of research. Gait Posture 2002;16:1-14.

36. Andersson G, Yardley L, Luxon L. A dual task study of interference between menta activity and control of balance. Am J Otol 1998;19:632-7.

37. Chau N, Gauchard GC, Siegfried C, et al. Relationships of job, age, and life conditions with the causes and severity of occupational injuries in construction workers. Int Arch Occup Environ Health 2004:77:60-6.

38. Edworthy J, Loxley S, Dennis I. Improving auditory warning design: relationship between warning sound parameters and perceived urgency. Hum Factors 1991:33:205-31. 